\title{
Forthcoming 'Special Topic Sections'
}

\section{Addiction Research}

Qualitative Research in the European Union

Guest editors: Richard Hartnoll (Barcelona), Jane Fountain (London)

The European Monitoring Centre on Drugs and Drug Abuse (EMCDDA) has been supporting a number of exercises designed to strengthen and develop the role of qualitative research in European drug epidemiology. These activities have included commission of an inventory, synthesis and review of qualitative research across the EU and sponsoring a networking meeting where researchers interested in qualitative methodology will have the opportunity to share experiences and discuss possibilities for collaborative projects. To complement these activities, European Addiction Research is producing a special issue on the topic.

Early Developmental Stages of Substance Disorders

Guest editors: H. U. Wittchen, C.B. Nelson (Munich)

The co-occurrence of mental and substance disorders is an important focus in the area of mental health research, especially among young people where the consequences of these outcomes has a long-term impact on family, education and career development. In this special section, we report baseline findings from a longitudinal panel study of adolescents and young adults focusing specifically on patterns of licit and illicit substance use and the association between these patterns of use and pre-existing psychiatric disorders. The section will conclude with a discussion of problems in assessing disorder prevalence and patterns of substance use in young populations.

Concepts and Results of Addiction Research in Children, Adolescents and Families

Guest editor: U. Knölker (Lübeck)

Addiction in children, adolescents and families has long been an underdeveloped area of psychiatric research. In the last 10 years, there has been a considerable increase in drug consumption in this age group, the age of the first contact with drugs has decreased and synthetic 'designer drugs' pose new questions. Several attempts have therefore been made to develop and test diagnostic and therapeutic methods. In this issue, first empirical results of diagnostics, clmical epidemiology, of research in therapy and in comorbid disorders are presented. Guidelines for further research and connections with research strategies in adults are discussed.

Quality of Care

Guest editors: M. Krausz (Hamburg), W. Fuchs (Zurich)

The research and the discussion on quality of care is a key issue in clinical addiction research these days. Quality assurance systems are also discussed under the aspect of restructuring therapy systems, and therefore they affect a wide range of political, clinical and research problems. We will try to present a thorough general view of the basic epidemiological and clinical problems, the documentation standards as well as a survey of the standards of care at a European level.

Addiction and the Law

Guest editor: H.-J. Albrecht (Dresden) 
In times of deregulation, the question of adequate control arises with fresh actuality. The intersection point of prevention, therapy and law reveals the differences of conceptions, interpretations and interests, which make it very hard to reach a commonly supported strategy. The focus of this issue will be the legal handling of addiction in different European countries. Same problems - different approaches, this comparison could be a very productive frame for an essential area of research.

Addiction Research in Central and Eastern Europe

Guest editors: Janusz Sieroslawski (Warsaw), Paul Griffiths (London)

The political and social changes that have occurred and are occurring in Central and Eastern Europe have been accompanied by dramatic changes in both the scale and nature of substance misuse in the region. There is an urgent need to better understand these changes if the potential for serious health consequences, both for the area and neighbouring countries, is to be avoided. With regard to drug misuse, prevalence appears to have gone, in some areas, from virtually zero to a level comparable with western European countries. Despite the importance of understanding the changes that are occurring, there remains a chronic lack of contemporary quality research information on the area. To help remedy this problem, European Addiction Research is producing a special issue on the region. Submissions are invited that address this topic on substance use and contributions from researchers based in the region are particularly welcome. K A RGER. (C1997S. Karger AG, Basel Fax+41613061234 E-Mail karger@karger.ch www. karger. com 